\title{
Práticas pedagógicas: contribuindo para a formação do aluno com Transtorno do
}

\section{Espectro Autista (TEA)}

\author{
Pedagogical practices: contributing to the training of the student with Autistic Spectrum Disorder
}

(ASD)

Prácticas pedagógicas: contribuyendo a la formación del estudiante con Trastorno del Espectro

Autista (TEA)

\section{Resumo}

A temática "Práticas Pedagógicas: Contribuindo para a formação do aluno com Transtorno do Espectro Autista (TEA), tem como Objetivo descrever uma revisão de literatura sobre a importância dessas práticas para a evolução do educando com esse transtorno, em relação ao acesso de materiais adaptados a essa criança com TEA na escola regular. Trata-se de um artigo de cunho bibliográfico que inicialmente abordará um breve histórico e a descrição das etapas do TEA e suas Práticas pedagógicas para uma inclusão significativa, abordará a importância dos Materiais adaptados para sua evolução. O Material e o Método, foram selecionados por meio de pesquisas e buscas eletrônicas, artigos, revistas e livros, os quais descreveram que, para que haja a inclusão escolar é necessário que a escola venha atender de forma plena a especificidade deste aluno, e assim garantir o seu acesso/permanência, bem como desenvolver sua autonomia, interações, e suas potencialidades. Pesquisar o TEA e a inclusão contribui para ampliar o conhecimento na área, contudo faz-se necessário o atendimento e cumprimento das Legislações e das Políticas Públicas destinadas a este educando. Nesta perspectiva, a temática reafirma a relevância, que todos compreendam e aceitem a diversidade humana, e contribuam na construção de uma sociedade justa e igualitária, oportunizando a convivência com outros alunos da mesma faixa etária, estimulando as suas capacidades interativas, através das práticas pedagógicas e como resultado, a evolução cognitiva e social, entendendo que, todas as estratégias e recursos são fundamentais na construção de uma melhor qualidade de vida em todos os seus aspectos.

Palavras-chave: TEA; Inclusão escolar; Práticas pedagógicas; Material adaptado.

\begin{abstract}
The present study has the theme "Pedagogical Practices: Contributing to the education of students with Autism Spectrum Disorder (ASD). And as the main Objective to describe a literature review on the importance of pedagogical practices for the evolution of the student with Autism Spectrum Disorder (ASD), in relation to access and materials adapted to the child with autism in regular school. It is a bibliographic article that will initially address a brief history and description of the stages of the ASD, then reports on the Pedagogical Practices for a meaningful inclusion of the child with ASD, after addressing the importance of the Materials adapted to evolve the student with TEA. Material and Methods: were selected through electronic searches and searches, articles, magazines and books. In this context, it can be said that for school inclusion it is necessary for the school to fully meet the specificity of this child, so that it can guarantee the access / permanence of the child with autism in the school environment, as well as develop their autonomy, interactions, and their potential. Researching TEA and inclusion contributes to expanding knowledge in the area, however it is necessary to comply with and comply with the Legislation and Public Policies aimed at this
\end{abstract}


student. In this perspective, the theme reaffirms the relevance, that everyone understands and accepts human diversity, and can contribute to the construction of a fair and egalitarian society. Because giving children with autism the opportunity to live with others of the same age group contributes to stimulating their interactive abilities. No less relevant, the pedagogical practices offered to this student are decisive for their cognitive and social evolution, that is, all strategies and resources are fundamental in the construction of a better quality of life in all its aspects. Final Considerations: The present study sought to describe the importance of Pedagogical Practices for the evolution of students with ASD, seeking to expand new knowledge on the subject and the benefits of including this student in regular education.

Keywords: Autism; Pedagogical practices; School inclusion and adapted material.

\section{Resumen}

El presente estudio tiene como tema "Prácticas pedagógicas: Contribuir a la educación de estudiantes con Trastorno del Espectro Autista (TEA). Y como objetivo principal describir una revisión de la literatura sobre la importancia de las prácticas pedagógicas para la evolución del alumno con Trastorno del Espectro Autista (TEA), en relación al acceso y materiales adaptados al niño con autismo en la escuela regular. Se trata de un artículo bibliográfico que inicialmente abordará una breve historia y descripción de las etapas del TEA, luego informa sobre las Prácticas Pedagógicas para una inclusión significativa del niño con TEA, luego de abordar la importancia de los Materiales adaptados para evolucionar al alumno con TÉ. Material y métodos: fueron seleccionados mediante búsquedas y búsquedas electrónicas, artículos, revistas y libros. En este contexto, se puede decir que para la inclusión escolar es necesario que la escuela atienda plenamente la especificidad de este niño, de manera que pueda garantizar el acceso / permanencia del niño con autismo en el ámbito escolar, así como desarrollar su autonomía., interacciones y su potencial. Investigar la TEA y la inclusión contribuye a ampliar el conocimiento en el área, sin embargo es necesario cumplir y cumplir con la Legislación y Políticas Públicas dirigidas a este estudiante. En esta perspectiva, el tema reafirma la relevancia, que todos comprendan y acepten la diversidad humana, y puedan contribuir a la construcción de una sociedad justa e igualitaria. Porque darles a los niños con autismo la oportunidad de convivir con otras personas del mismo grupo de edad contribuye a estimular sus habilidades interactivas. No menos relevantes, las prácticas pedagógicas que se ofrecen a este alumno son decisivas para su evolución cognitiva y social, es decir, todas las estrategias y recursos son fundamentales en la construcción de una mejor calidad de vida en todos sus aspectos. Consideraciones finales: El presente estudio buscó describir la importancia de las Prácticas Pedagógicas para la evolución de los estudiantes con TEA, buscando ampliar nuevos conocimientos sobre el tema y los beneficios de incluir a este estudiante en la educación regular.

Palabras clave: Autismo; Prácticas pedagógicas; Inclusión escolar y material adaptado.

\section{Introdução}

O presente artigo com tema Práticas Pedagógicas: Contribuindo para a formação do aluno com Transtorno do Espectro Autista (TEA) surgiu após o estágio supervisionado em Educação Especial, onde foi acompanhado um aluno com TEA, através dessa prática nasceram várias dúvidas quanto ao aprendizado de uma criança atípica, sabendo que a interação professor e aluno são a base desse processo, e sem comunicação não há como obter, entende-se que as dificuldades são inúmeras, pois um aluno com TEA acaba sendo na maioria das vezes excluída das atividades do grupo que estar inserido, dificultando ainda mais o aprendizado. O tema estará inserido na atualidade em que vivemos, mesmo com indício de pesquisa desde 1988 por Aspeger.

Uma criança com TEA segundo Pereira (1998) tem dificuldade ao nível de interação social, comunicação verbal e não verbal, e ao nível de atividades lúdicas. O adulto se comunica através da fala, escrita, e expressões, já as crianças em suas fases de desenvolvimento, se comunicam de forma lúdica através de brincadeiras, quando não tem esta comunicação a prática se torna desafiadora, pois dificilmente haverá apropriação do conhecimento.

A pesquisa foi desenvolvida para desmitificar o imaginário social o qual diz que o aluno com TEA não pode evoluir, pois durante algumas experiências em sala de aula com as ferramentas corretas adaptadas para cada criança, mesmo com o transtorno no níivel grave passam a conhecer a leitura e a escrita e assim se apropriar do mesmo.

O artigo também trará esclarecimentos sobre a origem do TEA, e quais contribuições foram feitas para o manejo com alunos com este transtorno, onde fará um breve relato sobre as teorias que foram surgindo como: Psicológicas, Biológicas e Cognitivas e qual mais explica a origem do TEA. 
Sabe-se que há inúmeras questões que norteiam este tema, pois como se não bastante as dificuldades diárias enfrentadas pela família e a criança que tem este transtorno, existem um preconceito que gera a exclusão, e de certa forma, limitando ainda mais a criança e consequentemente trazendo prejuízos ainda maiores. A partir desta temática, surgiram vários questionamentos, como: será se tem acontecido a inclusão do aluno com TEA? E os recursos (práticas pedagógicas) apresentados são de acordo com sua especificidade?

O objetivo deste trabalho é discorrer sobre a evolução do aluno com TEA através das práticas pedagógicas, para então fomentar tais práticas e conceder maiores benefícios não somente para aluno, professor, família, mas consequentemente, para sociedade.

\section{Quadro Teórico}

\subsection{Breve Histórico: As do Transtorno do Espectro Autista (TEA).}

A palavra autismo vem do grego "autos" que significa "próprio", ou seja, nesse contexto, o Autismo indica o desprezo com o mundo exterior, auto grau de concentração consigo mesmo, o mesmo aparece nos três primeiros anos de vida e acomete cerca de 20 entre cada 10 mil nascidos, sendo quatro vezes mais comum no sexo masculino do que no feminino. Independente da raça, etnia ou classe social, qualquer família pode vir a ser acometida pelo Transtorno do Espectro Autista.

O termo autismo foi usado pela primeira vez pelo psiquiatra suíço Eugen Bleuler, este o descreve como um grupo de traços relacionado à esquizofrenia, anos depois o psiquiatra austríaco Leo Kanner, por meio de pesquisas em um grupo de crianças, pôde perceber que tais traços, apareciam na primeira infância, respondendo de maneiras incomuns ao ambiente.

No mesmo ano das pesquisas de Leo, Hans Asperger, também psiquiatra austríaco, observou pelo padrão de comportamento e habilidades, tais sintomas ocorriam principalmente em meninos, o mesmo descrevia essas crianças como pequenos professores, pois sua habilidade com tais temas era discorrida detalhadamente, Asperger (1980) foi considerado como um dos pioneiros dos estudos do Autista a partir da década de 1980.

Após muitos anos de pesquisas e estudos, em 1970 através da psiquiatra inglesa Lornan Wing, mãe de uma criança autista, cunhou o termo síndrome de Aspeger, referindo-se ao psiquiatra Hans Asperger, o trabalho dessa psiquiatra revolucionou o mundo do autista, pois foi uma das maiores e mais importantes pesquisas na relação do mundo autista.

\subsection{Tríade de Lorna Wing}

Lorna Wing, na década de 70 realizou um estudo epidemiológico que permitiu concluir que todas as crianças diagnosticadas com Transtorno do Espectro Autista (TEA), apresentam uma tríade de características muito específicas, e que se agrupavam nos seguintes sintomas: limitação de participar de convívio social; forte diminuição da capacidade de participar do convívio social, o qual dificulta a comunicação receptiva e expressiva; e redução do poder imaginativo e fantasioso, resultando num repertorio comportamental limitado, as estes três sintomas deu-se o nome de: Tríade de Lorna Wing.

(...) É esta tríade que define o que é comum a todas elas, consistindo em dificuldades em três áreas do desenvolvimento mas nenhuma dessas áreas, isoladamente e por si só, se pode assumir como reveladora de "autismo". É a tríade, no seu conjunto, que indica se a criança estará, ou não, a seguir um padrão de desenvolvimento anómalo (...) (Wing \& Gould, 1979, p.17)

Segundo Pereira (2000), os três aspectos essenciais da Tríade de Lorna Winh são dificuldades ao nível da interação social com os outros, ao nível da comunicação verbal e não-verbal e por último ao nível das atividades lúdicas e imaginativas, ou seja, suas principais características, permitem a clareza do Transtorno do Espectro Autista (TEA). 


\subsection{Etiologia}

Várias teorias foram propostas para determinar qual a origem do Transtorno do Espectro Autista (TEA), no entanto, não é concebida qualquer etiologia específica, por se tratar de uma perturbação complexa em que nenhuma pessoa é igual a outra, logo, o mais provável, é que esta perturbação seja originada por múltiplos fatores Carr (2006); et al. (1993). Das teorias que foram surgindo estas se dividiram em três: as teorias psicogênicas, as teorias biológicas e as teorias cognitivas.

Teorias psicogênicas: mais predominante nos anos 50 e 60, foram uma das primeiras e principais explicações para o Transtorno do Espectro Autista (TEA), e sugerem que este é um distúrbio emocional cuja origem se encontra no ambiente próximo da criança, não decorrendo de uma perturbação biológica (as crianças nascem "normais"), e traduzindo-se numa resposta desadaptada a um ambiente desagradável, mais do que um déficit inato Garcia (2013). Como tal, a criança refugia-se no seu mundo em resposta ao tratamento frio e obsessivo que recebe do ambiente em que está inserida.

Considerou que as singularidades psicológicas dos pais das crianças comam autismo se traduziam em relações distorcidas e patológicas com os seus filhos, e estavam na origem da síndrome autista (...) [além disso], interpretava o autismo predominantemente como uma perturbação emocional.” Marques (1998, p. 44).

Pode-se descrever que a teoria psicogenética, desenvolve a tese que uma mãe fria sem afeto, permitirá que tal criança desenvolva o Transtorno do Espectro Autista (TEA) o antigo autismo, já que o mesmo devido sua falta de ação afetiva, segundo a teoria acima descrita, durante o desenvolvimento dessa criança, constantemente recebia resposta desadaptativa em relação ao afeto.

Devido essa teoria de psicogenética, em relação ao Transtorno do Espectro Autista (TEA), nota-se que por meios de estudos na época, efeito não muitos positivos em relação as pessoas responsáveis por essas crianças com o Transtorno do Espectro Autista (TEA), pois os mesmos se sentiam culpados pela falta de afetividade em relação a essas crianças.

As teorias biológicas: defendem que as teorias clínicas do Transtorno do Espectro Autista (TEA), refletem problemas de neurológicos, pois através de estudos e pesquisas, verificou-se por meio da associação do autista na época, que Transtorno do Espectro Autista (TEA), veio associado através de vários distúrbios biológicos como: rubéola pré-natal, paralisia cerebral, meningite e outros, e devido a isso o Transtorno do Espectro Autista (TEA), resulta também de perturbações do sistema nervoso central, o qual afeta a linguagem, o cognitivo e o intelectual.

Mesmo com tantos estudos e pesquisas pelo qual levaram a teoria biológica afirmarem que o Transtorno do Espectro Autista (TEA), é resultante de fatores biológicos, pode-se descrever que dentro dessa teoria biológica, há evidências de outra teoria a respeito, como a questão genética, porém mesmo com tantas afirmações genéticas para o Transtorno do Espectro Autista (TEA), antigo autismo, a mesma não se tornou perfeita.

[...] apesar de ter vindo a ser detectada uma grande variedade de anomalias genéticas em indivíduos com perturbações do espectro do autismo, a forma de como essa anomalia afeta o desenvolvimento cerebral ainda não é conhecida. (Marques1998, p. 53).

Teorias psicológicas: tal teoria segundo os últimos trinta anos tem se sobrepondo em relação as outras teorias, o autor Marques (1998), atribuiu a não informação do Transtorno do Espectro Autista (TEA), em relações as informações verbais, ao quais as recebiam de forma neutra, sem significação, pois tais respostas estereotipadas, resultado de testes cognitivos, permitiram descrever a representação dessa criança como representação mental inferior, causando assim dificuldades de aprendizagem. 
Os autistas são, assim, incapazes de extrair regras ou de estruturar experiências tanto nos domínios verbais como nãoverbal, o que torna compreensível a sua notória dificuldade em realizar tarefas orientadas por leis complexas como a linguagem e as interações sociais." (Marques, 1998, p. 60).

\subsection{Definição do Manual Diagnóstico e Estatístico de Distúrbios Mentais DSM V.}

No ano de 2013, especificamente no dia 18 de maio de 2013, foi publicado pelo DSM-V o novo Manual Diagnóstico e Estatístico de Transtornos Mentais da Associação Psiquiátrica Americana, resultado de dose anos de estudo, por meios de pesquisas de campo, realizado por centenas de profissionais, permitindo assim nova classificação, e reformulação e exclusão de diagnósticos, como no lugar de Transtorno Autista (DSM-IV), ficou Transtorno do Espectro Autismo (TEA).

Essa reformulação do DSM-V, permitiu a o entendimento desses transtornos, ao quais de forma individual, os mesmos tinham seus próprios diagnósticos segundo o DSM-IV, entendendo que as Síndromes acima citadas, fazem parte do Transtorno do Espectro Autista (TEA), saindo apenas a Síndrome de Rett, pois tal Síndrome não faz parte dos critérios do Transtorno do Espectro Autista (TEA), pois tem uma entidade própria, diferentemente do Transtorno do Espectro Autista (TEA)

Com o DSM-V publicado no ano de 2013, veio o aparecimento da nova nomenclatura como: Transtorno do Espectro Autista (TEA), permitindo a facilitação do diagnóstico e desenvolvimento dessa criança de forma clara e objetiva, tanto para os profissionais da saúde, pais, assistentes sociais, pessoas relacionadas a essa síndrome e professores, e assim a redução do Transtorno do Espectro Autista (TEA) em três: leve, moderada e severa descrita abaixo:

Leve: Nível um (1), a mesma "exige apoio”, em relação à comunicação social, na interação social, mesmo fazendo conversações com outras pessoas de forma falhadas, pois não há entendimento. No comportamento restrito e repetitivo: problemas para organização e planejamento, inflexibilidade do comportamento, dificuldade em trocar de atividades e obstáculos de independência.

Moderado: Nível dois (2), a mesma "exige apoio substancial”, e na relação da comunicação social verbal e não-verbal, a mesma possui graves déficits nas habilidades de comunicação social, dificuldade de iniciar interação social, dificuldade de abrirem conversações com outras pessoas e sua comunicação não-verbal acentuadamente estranha, todas essas características possuem níveis Em relação ao comportamento restrito e repetitivo, há dificuldade de lidar com as mudanças das pessoas, , os comportamentos restritos e repetitivos aparecem com frequência, sobrem e tem dificuldades de mudar focos ou ações.

Severo: Nível três (3), "exige apoio muito substancial”, e em relação à comunicação social há prejuízos graves de funcionamento em relação à comunicação social verbal e não-verbal, e na relação da interação social, a grande limitação em dar início em conversações. Na relação do comportamento restrito e repetitivo, o comportamento é inflexível, extrema dificuldade em lidar com mudanças, seu comportamento restrito e repetitivo interfere completamente no seu funcionamento em todas as áreas, possui grande dificuldade de mudanças ao ponto de trazer grande sofrimento.

É nesse contexto acima que existe a possibilidade de apresentar os seis principais grupos existentes no Transtorno do Espectro Autismo (TEA), mesmo a não existindo um teste para realizar o diagnóstico do Transtorno do Espectro do Autismo, pois tais diagnósticos para serem concretizados necessitam de uma equipe de multiprofissionais, envolvendo Neuro, Psicólogos, professores, família e cuidadores dessa criança.

O sistema de Diagnóstico Manual Diagnóstico e Estatístico de Transtornos Mentais (DSM-V) e Classificação Internacional de Doenças (CID-10) baseiam-se pelos seus critérios comportamentais “A, B, C, D e E”, onde o “A”, apresenta déficits que persistem na comunicação social e interação social, subdivididos em 1, 2, e 3; O critério "B", apresentam padrões restritos e repetitivos de comportamento, também subdivido em 1, 2, 3 e 4 pelo DSM-V. 
No critério "C" apresenta os critérios contidos no "A e B", porém junto com o critério "C" que é justamente os sintomas apresentados precocemente; No critério " $\mathrm{D}$ " os sintomas causam prejuízos clinicamente significativos, e no critério "E”, não é tido como deficiência intelectual ou por atraso global, pois não está abaixo do nível geral do desenvolvimento.

\section{Metodologia}

A presente pesquisa foi elaborada com base em artigos científicos, livros e revistas que abordam assuntos a respeito da inclusão, com foco nas práticas Pedagógicas para a inclusão de alunos com TEA no âmbito escolar do ensino regular. Refere-se a uma pesquisa bibliográfica, de natureza exploratória, nos principais fundamentos teóricos sobre o tema trabalhado. Utilizou-se também, para uma maior compreensão de estudos nacionais, a base de dados do Google Acadêmico, SciELO (Scientific Eletronic Library Online) e autores como Dunst e Bruder (2002), Rodrigues (2003), Karagiaannis, tainback e Stainback (1999) Brasil, LDB (2006), DSM-5 (2013) entre outros, que abordam o autismo, as práticas pedagógicas, e a inclusão no ensino regular. Dos referenciais bibliográficos foram selecionadas publicações de 1984 a 2012. Como base de pesquisa utilizou-se as seguintes palavras chave: Autismo.

Práticas Pedagógicas. Inclusão escolar e Material adaptado. O estudo foi realizado por meio de leituras seletiva, analítica e interpretativa do material selecionado, para verificar a importância de seus conteúdos para a elaboração do presente trabalho sobre as práticas pedagógicas para a inclusão do educando com TEA, por meio dos materiais adaptados nas escolas de ensino, regular Gil (2002).

\subsection{Práticas Pedagógicas para uma inclusão significativa do Transtorno do Espectro Autista (TEA)}

\subsection{Educação Escolar Inclusiva e um Breve Histórico}

A partir da Antiguidade (Antigo Egito) os deficientes ocupavam um lugar na sociedade, já na Antiguidade Clássica (Roma, Grécia e Antenas), estes eram negligenciados e considerados a degeneração da raça humana, logo, deveria ser eliminada devido ao transtorno que geravam á sociedade. Contudo na Idade Média, considerada Era Cristã, estes passam ser amados e aceitos, deixam de ser vistos como castigo de Deus. Porém, até meados do século XVIII, as noções de deficiência foram marcadas pelo misticismo e preconceito.

Ainda na Idade Média, com a valorização do ser humano, não se abandona e começa o processo de institucionalização, onde são retirados de suas casas e levados para as igrejas. Somente a partir da metade do século XX, mediante estudos realizados na Dinamarca, chegou-se ao princípio da Normalização, que busca criar condições de vida as pessoas com retardo mental, ou seja, esta tem como objetivo tornar os serviços e oportunidades iguais para todos.

Em decorrência destes acontecimentos a Educação Especial no Brasil, data do século XVIII e início do século XIX com a influência do Liberalismo, que traz consigo a idéia de liberdade para todos os indivíduos, pautado na democratização dos direitos para todos os cidadãos, influenciando assim a educação das pessoas com deficiência no Brasil.

Neste cenário, podem-se destacar alguns dos principais documentos nacionais e internacionais que norteiam uma Educação Inclusiva, tais como: A Lei de Bases do Sistema Educativo de 1986, que reconhece a cada cidadão o direito de acesso à escolaridade básica bem como o direito ao sucesso escolar. O acordo de Jomtien de 1990, que propõe a garantia de uma educação básica para todos, numa escola para todos; A Declaração de Salamanca de 1994, que reconhece que cada criança possui características, interesses, capacidades e necessidades de aprendizagem próprias a que a escola deve corresponder de maneira inclusiva; Resolução CNE/CBE n 2 (2001), institui diretrizes nacionais para a educação especial na educação básica e em todas as modalidades; Conversão Interamericana para a Eliminação de Todas as Formas de discriminação contra as pessoas com deficiência 2001, visa eliminar toda a discriminação contra a pessoa com deficiência, e mais recente a Lei 12.764/2012, que vem garantir a proteção dos Direitos da Pessoa com Transtorno do Espectro Autista 
(TEA) onde determina em seu $\S 2^{\circ}$ que a pessoa com transtorno do espectro autista é considerada pessoa com deficiência, para todos os efeitos legais.

Percebe-se que todas elas direcionam-se para a existência de uma escola inclusiva, que venha oferecer oportunidades educacionais adequadas e que atendam às necessidades especificas do educando com Transtorno do Espectro Autista (TEA) afim desenvolver todos os seus aspectos (cognitivo, afetivo, emocional e afetivo) juntamente com outras crianças na escola regular. Segundo Baumel (1998) trata-se então da criação de uma escola que aceite todas as diferenças e se adapte à variedade humana, criando um ambiente propício ao desenvolvimento das potencialidades individuais.

Neste âmbito, pode-se descrever o termo inclusão, como significado de: o ato ou efeito de incluir, de fazer parte, já em relação ao contexto escolar, significa incluir alguém que tenha algum tipo de deficiência no meio de pessoas que não tem. Nota-se que em relação ao aluno com Transtorno do Espectro Autista (TEA) esta é fundamental, pois não tem como se falar de inclusão sem antes pensar no outro.

Karagiaannis, Stainback e Stainback (1999), definem a inclusão, como prática de inclusão de todos, e isso independente de seu talento, dificuldade, deficiência, origem cultural, origem social, ou seja, prover a satisfação para todos de acordo com suas necessidades, permitindo assim, a união entre alunos, familiares, educadores e membros da comunidade, lutando pelo direito de ocuparem seu lugar, sua colaboração e participação dos mesmos na escola.

Ainda na visão dos autores, os mesmos salientam o benefício da inclusão. Pois a mesma permite a pessoa com deficiência vivenciar oportunidades de experiências reais, preparando-o para o melhor convívio em comunidade, e assim desenvolverem suas habilidades, permitindo assim a superação de tais dificuldades existentes na pessoa com deficiência.

Foi exatamente no ano de 1990, pelo qual o termo inclusão (do inglês, inclusion), começou a ser mencionado, dando sentido na educação especial nos países de Estados Unidos e Suécia, Göransson; Nilholm, (2009), após alguns anos mais tarde, no mesmo ano, veio à circulação da Declaração de Salamanca, realizada entre os dias 7 e 10 de junho de 1994 na cidade espanhola de Salamanca, princípios das Organizações das Nações Unidas, para a Educação, a Ciência e a Cultura (UNESCO), o qual introduz a perspectiva de inclusão na educação.

Mônica Kassar (2011) descreve o marco relevante para educação inclusiva, onde após a segunda guerra mundial, alguns países passaram a garantir a matricula para crianças com deficiências nas salas de aulas, possibilitando assim oportunidades de expandir essa inclusão por meio de profissionais e interessados da área da educação, um desses países é o Estados Unidos, chegando ao ponto de atingir o Brasil até os dias de hoje.

\subsection{Desafios da escola frente á Inclusão Escolar}

Segundo Rodrigues, (2003), a noção de inclusão tem relação com a diversidade do mundo escolar, onde não há mais lugar para exclusões, ou seja, para que a escola seja de fato para todos, ela precisa atender três eixos fundamentais: transformações curriculares, metodológicas e organizativas.

Pois a presença de alunos com Transtorno do Espectro Autista (TEA) obrigará as escolas a adaptações e a novas práticas pedagógicas. Isso significa o desenvolvimento de competências especificas para os professores do ensino regular. Para o autor as dificuldades vão desde a identificação dessas chamadas necessidades especiais até o conhecimento de técnicas, adaptações curriculares e de avaliação, bem como necessidades de conhecimento das relações da escola com a família, tanto dos alunos com Transtorno do Espectro Autista (TEA) como para os alunos sem necessidades educacionais.

Para Ferreira (2003), incluir tem uma importância fundamental, pois diminui todo e qualquer tipo de exclusão, permitindo a participação coletiva e individual do educando. Promover a inclusão significa uma mudança de postura e do olhar acerca da deficiência. Implica uma quebra de paradigmas, e a reformulação do nosso sistema de ensino para a conquista de 
uma educação inclusiva, implica também o cumprimento do princípio da normalização, que tem como objetivo tornar os serviços e oportunidades iguais para todos.

Em outros termos, para atender o educando com Transtorno do Espectro Autista (TEA), as escolas atuais devem rever seus Projetos Políticos Pedagógicos a partir de uma gestão democrática e inclusiva, visando uma política coletiva e participativa em prol do que determina a Lei 12.764/201. Contudo, os sistemas de ensino devem dispor de recursos e condições de acesso ao currículo, promovendo materiais didáticos, espaços e equipamentos que venham atender a especificidade deste educando. Ainda de acordo a LDB 9394/96, cabe à escola aprender a conviver com as diferenças e traçar caminhos que levem de fato a inclusão.

É por tudo isso que Alexandre Mapurunga, Presidente da Associação Brasileira para Ação por Direitos das Pessoa com Transtorno do Espectro Autista (TEA), a inclusão começa com a chegada desse aluno à escola, mas é preciso também garantir sua permanência e aprendizagem, a fim de oportunizar a diversidade e a cultura escolar.

Por essa razão, a educadora Maria da Paz Castro acredita ser importante observar com o aluno com Transtorno do Espectro Autista (TEA) também fora do contexto escolar, uma vez que o seu processo de desenvolvimento será incentivado todas as vezes que o mesmo estiver em situações legitimas de convívio, isso dentro e fora do seu convívio de costume.

Para Palhares e Martins (2010), as escolas procuram se eximir desse processo inclusivo alegando questões financeiras, condições de trabalho do professor, a falta de recursos educacionais especiais, bem como acompanhamento e avaliação de intervenção de políticas públicas. As autoras salientam que a melhoria da qualidade de um ensino inclusivo depende dos sistemas de ensino, da vontade política e do comprometimento de seus gestores em querer fazer acontecer essa inclusão.

\subsection{Práticas Pedagógicas para o aluno com Transtorno do Espectro Autista (TEA)}

\subsection{Intervenção Precoce}

Segundo Dunst e Bruder (2002), a Intervenção precoce é definida como uma prática que diz respeito aos serviços, apoios e recursos necessários para responder às necessidades e oportunidades que incentivem a aprendizagem e desenvolvimento da criança com Transtorno do Espectro Autista (TEA), bem como o apoio as famílias afim de que as mesmas possam desempenha um papel ativo, no desenvolvimento e assistência dessa criança.

Outro aspecto é quanto mais cedo o agnóstico for feito, melhores serão os resultados, pois o ideal seria uma criança com Transtorno do Espectro Autista (TEA) ser identificada antes dos três anos de idade. Porem, na prática, os estudos científicos mostram que a consulta com um especialista em Desenvolvimento só ocorre por volta dos quatro anos e que o diagnóstico é muitas vezes feito apenas aos cinco anos de idade o que compromete o processo evolutivo.

Nesta perspectiva, para Correia (2005). Uma das abordagens utilizadas na intervenção precoce é a abordagem desenvolvimentista que procura identificar as características autistas que se afastam do que é considerado desenvolvimento normal, de forma a retomar o percurso do desenvolvimento típico que a criança com autismo não seguiu devido às suas dificuldades de interação e comunicação.

Em relação a essa abordagem Prizant (2000) defende um modelo sócio pragmático desenvolvimentista o (DSP) e apresenta o modelo de intervenção Social (SCERT) (modelo de intervenção comunicação-social, regulação emocional, apoio transacional) que vem para promover as habilidades socioemocionais e de comunicação da criança com Transtorno do Espectro Autista (TEA).

Nesse sentido, o modelo DSP defende que é preciso focalizar a iniciação e a espontaneidade na comunicação, seguindo o foco de atenção e motivação da criança, ou seja, construir a partir do seu repertório comunicativo atual, através de recursos que façam parte do contexto da criança. 
Enquanto, o modelo SCERTS refere-se aos déficits ocultos centrais que afetam as crianças com Transtorno do Espectro Autista (TEA), que são: os déficits em comunicação e linguagem, relacionamento social, reciprocidade socioemocional, e processamento sensorial. Sua abordagem é voltada para o individualismo, uma vez que o perfil das crianças apresenta características diferentes e as famílias variam em termos de habilidades, recursos e apoio. O tratamento é voltado para estratégias clínicas que envolvem a escola e a família.

Por outro lado, os déficits no relacionamento social e reciprocidade socioemocional são abordados pelas estratégias desenvolvidas pelo modelo (DIR) (modelo desenvolvimentista, de diferença individual, baseado no relacionamento) dos autores Greenspan e Wieder, (2000).

Esse modelo enquadra-se também numa abordagem desenvolvimentista e tem como foco possibilitar que a criança conheça a si mesma, a fim de desenvolver suas capacidades linguísticas, sociais, comunicação e pensamento abstrato e lógico.

\subsection{Métodos para evolução do aluno com Transtorno do Espectro Autista (TEA)}

A priori não existe um método especifico a ser aplicado no Transtorno do Espectro Autista, pois depende das características e comprometimentos de cada criança, uma vez que cada indivíduo é único. Porém, Escolas e Instituições que trabalham com Transtorno do Espectro (TEA), fazem uso dos seguintes métodos. No sentido educacional, deve-se pesquisar e buscar conhecer cada um, mas sua aplicação deve ser feita por um profissional habilitado, pois este identificará quais métodos, técnicas ou programas serão adequados ao aluno com a síndrome. Atualmente os métodos usados pelas escolas e instituições são:

TEACCH - (Tratamento e Educação para crianças com Espectro Autista (TEA)s e Crianças com déficits relacionados com a comunicação) é fundamentado na avaliação individualizada centrada na pessoa com Transtorno do Espectro Autista (TEA) e no desenvolvimento de um programa de ensino estabelecido a partir de suas habilidades, interesses (motivação) e necessidades. Adota uma perspectiva holística, levando em conta a relação família/criança. Outro objetivo busca tornar mais amplo as habilidades, além de atuar em sua autonomia para torná-lo o mais independente possível.

ABA - (Analise Aplicada do Comportamento) é feita com a finalidade de identificar habilidades que a criança já domina e ensinar aquelas que ele ainda não domina. As respostas negativas não são estimuladas, pelo contrário, a criança deve trabalhar apenas os comportamentos positivos. No estimulo de conhecimentos já adquiridos, é utilizada a base fundamental na teoria Estimulo - Resposta, ou seja, o indivíduo é condicionado a reagir, tendendo a repetir as respostas adequadas ao bom desempenho do processo de aprendizagem.

PECS - (Sistema de Comunicação por troca de figuras) sistema de comunicação através de imagem, é um método barato, fácil de aprender e pode ser aplicado em qualquer lugar, inclusive pelos pais em casa. Uma característica deste método é que as crianças iniciam o processo de comunicação, ou seja, são elas que iniciam a interação. Eles não aprendem a esperar ou depender dos adultos que podem satisfazê-las. Aprender o PECS tem conseguido grande efeito de reduzir as preocupações voltadas para o comportamento destas crianças, tanto nas escolas quanto em casa.

Diante do exposto, os métodos educacionais acima citados, de cunho visual são de grande relevância para a construção da aprendizagem da criança com Transtorno do Espectro Autista (TEA), uma vez que, seu pensamento é fragmentado, e pautado na previsibilidade. Por isso, usar o lado visual como recurso de substituição é possibilitar a pessoa com Transtorno do Espectro Autista (TEA), comandos compreensíveis sobre qual situação ele será exposto. Entretanto, vale ressaltar que mesmo diante dos vários métodos de intervenção, estes não solucionam os déficits, mas os mesmos vêm para somar com todos os trabalhos já pesquisados e comprovados nesta área, que buscam oportunizar melhoria na qualidade de vida da criança com Transtorno do Aspecto Autista (TEA) e de sua família. 


\subsection{Materiais Adaptados para uma Inclusão Significativa}

Segundo (Investigação na Escola Inclusiva, 2006). Um sistema educativo só pode ser considerado inclusivo quando reconhece que todas as crianças podem aprender; admite e respeita diferenças nas crianças, nomeadamente a idade, o sexo, a etnia, a língua, a deficiência/inabilidade, a classe social, o estado de saúde ou qualquer outra condição; admite que as estruturas, sistemas e metodologias de ensino têm de atender às necessidades de todas as crianças; não é restrito ou limitado por salas de aula numerosas nem por falta de recursos materiais. Uma escola inclusiva é assim, um tipo de comunidade educativa cujas práticas respondem à diversidade dos seus alunos, atendendo às necessidades emocionais, acadêmicas e sociais que os mesmos manifestam.

Em outros termos Góes (2008) define, o material pedagógico adaptado como "ferramenta e não como fim", o qual propicia a interação convivência, autonomia e independência nas ações, aprendizado de conceitos, melhoria de autoestima e afetividade". Contudo, é necessário o professor ter o conhecimento da diversidade e das características do seu aluno com Transtorno do Espectro Autista (TEA), para assim definir estratégias de ensino com o objetivo de desenvolver o seu potencial.

Para Baumelet (1998). Uma turma que acolha crianças diferentes terá inúmeros benefícios ao nível do desenvolvimento cognitivo e social, pois tanto as crianças com necessidade educacionais especiais, quanto as demais, se beneficiaram das interações e dos materiais adaptados, favorecendo o desenvolvimento de todos os alunos, sem exceção. Logo, o material adaptado possibilitará aos alunos mais desfavorecidos que avancem impulsionados pela interação social, sob a orientação do professor e com a colaboração dos colegas.

Desse modo, as crianças com Transtorno do Espectro Autista (TEA) irão evoluir em função das condições dos materiais adaptados e afetivas que os cercam. Pois o contato das crianças entre si reforça atitudes positivas, ajudando-as a aprender, a compreender, a respeitar e a conviver com as diferenças. "Todas as crianças, sem distinção, podem beneficiar das experiências obtidas no ambiente educacional e dos materiais adaptados" Ferreira (2003).

Ainda na visão de Baumelet (1998). É de suma importância que na construção desse material adaptado para o aluno com Transtorno do Espectro Autista (TEA), o professor tenha "consciência das dificuldades acadêmicas, comportamentais, sócio-emocionais e especifica dessa criança (...) e seja sensível e compreensivo, perante estas". É impreterível que o mesmo adapte as suas práticas a todos os níveis e aptidões, a fim de conduzir todos os alunos, sem exceção, ao sucesso educativo.

Desta forma, o material adaptado deve ser considerado pressuposto para evolução cognitiva e social do aluno com Transtorno do Espectro Autista. Porem ao refletirmos sobre a a importância dos mesmos como facilitadores no processo de ensino - aprendizagem, deve-se considerar as contribuições de Vigotsky (1991) que concebe o desenvolvimento nas relações sociais e em seu caráter histórico-cultural por meio da experiência social.

\section{Considerações Finais}

A partir das leituras realizadas sobre a temática, percebeu-se que para que haja uma educação que atenda a especificidades do aluno com TEA, é necessário o comprometimento por partes das políticas públicas, pais, professores e escola, pois além do envolvimento da escola e comunidade é necessário que a escola possua condições necessárias e adequadas a sua disposição para atender as necessidades e garantir o acesso e permanência desses alunos, para que os mesmos não venham ser apenas um número em sala de aula.

É notório que é preciso que, o professor tenha um olhar voltado as necessidades desse alunado, focando em suas potencialidades e não em suas dificuldades, para que assim ele se sinta incluído no mais amplo sentido da palavra, ou seja, sendo atendido e respeitado em sua especificidade. Outro ponto de relevância para a inclusão da criança com TEA é o currículo, Pois este deve priorizar a autonomia do sujeito, levando-o a capacidade de desenvolver atividades do cotidiano, quando a escola aplica na prática o que há na teoria, novos conhecimentos e comportamentos passam a ser desenvolvidos no 
aluno, ou seja, quando as praticas desenvolvidas e aplicada junto com a interação do aluno com TEA, não só o aluno com esse transtorno se desenvolvera, como também se desmitificará o imaginário social, que o aluno com TEA não se desenvolve.

\section{Referências}

Asperger, H. (1980). Autistic psychopathy in childhood. In U. Frith (Ed.), Autism and Asperger syndrome (pp. 37-92). Cambridge University Press. (Trabalho original publicado em 1944). [ Links ]

Aiello, A. L. R. Família Inclusiva. In: Palhares, M. S.; Marins, S. C. Escola inclusive. EdUFSCar, 2002.

American Psychiatry Association.Diagnostic and Statistical Manual of Mental disorders - DSM-5. (5th.ed.), American PsychiatricAssociation, 2013.

Baumel, R. C. R. C. (1998) escola inclusiva questionamento e direções. In: Baumel, R.C.R.C \& Semenghini, I. (ORG)Integrar-Incluir: desafio para a escola atual.

Carr, M. et al, Based Risk Identification. Technical Report CMU/SEI-93- TR-6. Software Engineering Institute, Carnegie Mellon University. USA. 1993.

Correia, O. B. (2005). A Aplicabilidade de um Programa de Intervenção Precoce em crianças com possível Risco Autístico.

Ferreira, M. Elisa Caputo e Guimarães, Marly. Educação inclusiva. Editora: DP \&A, 2003.

Ferreira, Lucia. (2011). Atividades fisicas inclusivas para pessoas com deficiência. 8.

Garcia, M. O indivíduo, a genética e a história.

Göransson, K.; Nilholm, C., L'éducation inclusive en Suède: idées, politiquesetpratiques. In: Benoit, Hervé; Plaisance, Eric (Dir.). La nouvelle revue de l'adaptation et de la scolarisation:l'éducation inclusive en France et dans le monde. Suresnes, hors série 5, 67-80.

Gil, M. (Coord.). O que as empresas podem fazer pela inclusão das pessoas com deficiência. Instituto Ethos, 2002.

Góes, R. S. de. O Material Pedagógico Adaptado como Ferramenta e não como Fim: uma Reflexão a respeito da Inclusão de Pessoas com Deficiência NeuroMotora. http://fórum.ulbratorres.com.br/2008/.../PALESTRA\%205\%20- \%20GOES.pdf

Greenspan, S. I., \& Wieder, S. (2000). A developmental approach to difficulties in relating and communicating in autism spectrum disorders and related syndromes.In A. M.

Wetherby, B. M. Prizant (Orgs.), Autism spectrum disorders.A transactional developmental perspective (pp.279-306). Baltimore: Paul H. Brookes.

Improvement Through Research In The Inclusive School, Estratégias e Práticasem Salas de Aula Inclusivas, IRIS 128735-CP-1-2006-1-BE-COMENIUS-C21.

Kassar, M. de C. M. Percursos da constituição de uma política brasileira de educação especial inclusiva. Revista Brasileira de Educação Especial, Marília, v. 17, p. $41-58,2011$.

Klinger, L. G., \& Dawson, G. (1992). Facilitating early social and communicative development in children with autism.In S. F. Warren \& J. Reichle (Orgs.), Causes and effects in communication and language intervention (pp.157-186).Baltimore: Paul H. Brookes.

Schaffner, C. B. \& Baswell, B. Dez elementos críticos para a criação de comunidades de ensino. In: Stainback, S. \& Stainback, W. Inclusão: Um guia para educadores. Tradução de Magda França Lopes. Porto Alegre: Artmed Editora S.A., 1999. p. 69 - 87.

Lei de Diretrizes e Bases da Educação Nacional - LDB. http://www.planalto.gov.br/ccivil_03/Leis/L9394.htm.

Lei N 12.764 , De 27 De Dezembro De 2012.Institui a Política Nacional de Proteção dos Direitos da Pessoa com Transtorno do Espectro Autista; e altera o $\S$ $3^{\circ}$ do art. 98 da Lei no 8.112 , de 11 de dezembro de 1990 .

Marques, C. (1998). Perturbações do espectro do Autismo: ensaio de uma intervenção construtivista desenvolvimentista com mães. DissertaçãodeMestrado não publicada. Faculdade de Psicologia e de Ciências da Educação, Universidade de Coimbra.

Pereira, M. E. C. (2000) Bleuler e a invenção da esquizofrenia Revista Latino americana de Psicopatologia Fundamental, III(1).

Prizant, B. M., Wetherby, A. M., \&Rydell, P. J. (2000). Communication intervention issues for children with autism spectrum disorders. In A. M. Wetherby\& B. M. Prizant (Orgs.), Autism spectrum disorders.A transactionaldevelopmentalperspectiv (pp.193-224). Baltimore: Paul H. Brookes.

Rodrigues, David (org.) “Inclusão e Educação: doze olhares sobre a Educação Inclusiva”, S. Paulo. Summus Editorial, 2003

Wing, L., \& Gould, J. (1979). Severe impairments of socialinteraction and associated abnormalities in childrenEpidemiology and classification Journal of Autism and Developmental Disorders, 9, 11-29.

Vigotsky, L. S. Aprendizagem e desenvolvimento intelectual na idade escolar. In: Vigotsky, L. S. et al. Psicologia e Pedagogia I: bases psicológicas da aprendizagem e do desenvolvimento. (2a ed.), Estampa, 1991. 